\title{
DESENVOLVIMENTO DE CENÁRIOS PARA AVALIAÇÃO DE AVISOS DE SEGURANÇA EM AMBIENTES VIRTUAIS
}

\author{
Reginaldo Schiavini \\ Faculdade de Arquitetura - Universidade de Lisboa \\ ergos@terra.com.br
}

Resumo: O objetivo deste estudo é apresentar a metodologia utilizada para desenvolver dois cenários a partir de um ambiente virtual. Foram utilizadas e adaptadas imagens provenientes deste ambiente virtual e retiradas da internet, bem como abordados os conceitos de realidade virtual, avisos e imersão. A importância do uso de cenários em estudos sobre comportamento consonante com avisos é muito grande, sobretudo quando se precisa modelar/selecionar envolvimentos virtuais. Tais cenários podem apoiar o raciocínio sobre situações de uso, antes mesmo destas situações serem criadas. O resultado obtido com esta metodologia foi o desenvolvimento de dois cenários diferentes: altruísta e egoísta, que apresentam características diferentes e que podem implicar em comportamentos divergentes ao usuário. $\mathrm{O}$ desenvolvimento destes dois cenários consistiu uma etapa inicial de uma pesquisa que pretende comparar os dois cenários para saber qual deles poderá exercer uma influência maior sobre o usuário frente a uma tomada de decisão.

Palavras-chave: Cenário, Aviso, Imersão, Realidade Virtual, Multimodal.

\begin{abstract}
The objective of this study is to present the methodology used to develop two scenarios from a virtual environment. Were used and adapted images from this virtual environment and taken from the Internet, as well as discussed the concepts of virtual reality, warnings, and immersion. The importance of using scenarios in line with studies on warnings behavior is very large, especially when you need to model/select virtual involvements. Such scenarios can support reasoning about situations of use, even before these situations are created. The results obtained with this approach were the development of two different scenarios: unselfish and selfish, which have different characteristics and may involve different user behaviors. The development of these two scenarios consisted of an initial step of a research that aims to compare the two scenarios to see which of them can exert greater influence on the user facing a decision.
\end{abstract}

Keywords: Scenario, Warning, Imersion, Virtual Reality, Multimodal. 


\section{INTRODUÇÃO}

Sabendo das potencialidades da aplicação da tecnologia na concepção de avisos de segurança e da importância do uso de cenários, este artigo tem como objetivo a descrição de uma metodologia para o desenvolvimento de cenários para serem incorporados em simuladores para segurança. Isto se dá em um contexto onde pretende-se desenvolver avisos de segurança eficazes, cujo problema é a avaliação da eficácia destes avisos.

Nesta pesquisa, o termo "Realidade Virtual" (RV) é usado para designar um sistema de imersão que utiliza mundos digitais interativos. O significado de cenário, corresponde a uma descrição (narrativa) que contém o papel dos atores, informação sobre os objetivos e metas à alcançar, assim como as sequências de ações que devem cumprir numa dada situação, no contexto definido. No processo de desenvolvimento e escolha dos dois cenários utilizados, pretendeu-se testar quais fatores psicológicos mais influenciavam na decisão do usuário.

Optou-se então, por utilizar dois tipos diferentes de cenários, a saber: egoísta e altruísta como sendo de comportamentos divergentes, ou até mesmo opostos, que podem influenciar na intenção comportamental do usuário. Para dar suporte a isto foram desenvolvidas duas narrativas escritas (uma para cada cenário) que simulam uma situação de perigo e o uso de imagens com avisos para proporcionar um maior entendimento e envolvimento por parte das pessoas. Para tornar mais fidedigno possível o grau de veracidade dos cenários que melhor representam os fatores psicológicos (como as características do comportamento egoísta e altruísta, e a percepção de urgência e risco) procurou-se criar situações que fossem o mais semelhante possível ao mundo real.

O problema principal deste artigo é como criar cenários. Como os cenários podem influenciar no processo de tomada da decisão dos usuários? Incialmente foi desenvolvido um cenário onde haviam componentes muito fortes em termos de influenciação junto aos usuários. A motivação para o não cumprimento do aviso era tão forte que poderia conduzir a um "efeito teto", ou seja, induzir o participante a ir em uma direção ou tomar uma determinada atitude. Por isto criou-se um cenário mais ameno em termos de ambiente e motivação. Entretanto, mesmo com a mudança do cenário, ele pode criar na pessoa um dilema entre o cumprir com uma informação que é apresentada por um contexto, em que esta pessoa pode ser forçada a não cumprir com esta informação.

\section{DESENVOLVIMENTO}

\subsection{Cenários}

Os cenários tem sido utilizados, hoje em dia, em uma diversidade de áreas. Como exemplo Carrol (2000) utiliza cenários no design de interação humanocomputador para vislumbrar e documentar atividades típicas e significativas no processo de desenvolvimento de softwares e interfaces gráficas. Em computação, segundo Alexander e Maiden (2004), um cenário é uma narrativa, que mais comumente descreve as interações previsíveis de funções de usuários e o sistema 
técnico. Um cenário tem um objetivo que normalmente é funcional. Os cenários são escritos em linguagem simples, com detalhes técnicos mínimos, de modo que as partes interessadas (designers, especialistas em usabilidade, programadores, engenheiros, gestores, especialistas em marketing, etc) possam ter um exemplo comum para concentrar suas discussões. Os cenários variam de histórias breves, às análises ricamente estruturadas, mas quase sempre, baseados na ideia de uma sequência de ações a serem realizadas. De uma forma resumida, o cenário é uma maneira mais fácil de comunicar uma ideia, através de uma história, permitindo uma visão do conjunto da situação.

Estes cenários podem apoiar o raciocínio sobre situações de uso, antes mesmo destas situações serem criadas. Segundo Alexander e Maiden (2004), os cenários precisam ter uma narrativa, que incluem sequências de ações e eventos, coisas que os atores fazem, coisas que acontecem com elas, mudanças nas circunstâncias e na configuração, e assim por diante. $O$ uso de cenários para a decisão em ambientes complexos é comentado por Cook et. al. (2007). Um exemplo de uso de cenários nestas condições é a simulação para cirurgias cardíacas conforme visto por Feltovich et. al. (2001).

\subsection{Avisos \& Realidade Virtual}

A finalidade básica dos avisos é fornecer informações que permitam às pessoas tomarem decisões seguras. Assim, uma questão importante no projeto de avisos é o tipo de informação que estes vão comunicar. Na literatura de avisos parece haver um consenso geral de que os avisos devem incluir informações sobre os riscos, consequências e instruções sobre o comportamento seguro (Laughery e Wogalter, 1997).

Os avisos podem ser utilizados em diversas maneiras (como sinais, rótulos, folhetos, etiquetas e outros). Eles podem ser estáticos ou dinâmicos. Os avisos estáticos utilizam um método de comunicação passivo. Diferentemente, os avisos dinâmicos ou de base tecnológica, como são também denominados, utilizam uma tecnologia mais avançada para informar e alertar um determinado perigo. Como característica, os avisos dinâmicos podem ser multimodais, permitir a personalização e ser resistente à habituação. Estes fatores fazem com que estes avisos sejam mais eficazes do que os estáticos (Wogalter e Conzola, 2002; Wogalter e Mayhorn, 2005; Duarte et. al. 2013).

Em relação à explicitação em avisos, tem-se a definição de "explicitação" do dicionário Webster's Collegiate Thessaurus: tão claramente expresso, para não deixar nenhuma dúvida sobre o significado. Segundo Laughery e Smith (2006) esta questão relativa a explicitação diz respeito a saber se existe a necessidade de fornecer informações sobre todas as três categorias de informação: riscos, consequências e instruções. $E$, dentro das diferentes categorias, a questão é saber quanto explícita a informação deve ser.

Para que estes testes possam se tornar mais eficientes, é preciso criar ambientes onde eles podem ter uma avaliação da situação segura para o usuário, a fim de criar um ambiente onde podemos controlar melhor as variáveis e ser o mais realista possível. 
A Realidade Virtual (RV) é um ambiente simulado por computador onde os usuários podem explorar e interagir com uma realidade artificial, enquanto a sensação de que eles estão em um lugar diferente de onde eles estão fisicamente. Um sistema RV é composto por hardware, software, uma interface de usuário e os fatores humanos, tais como a percepção, cognição e emoções (Gorini et. al. 2011). A RV é mais do que uma tecnologia de fantasia: é uma forma avançada de interação humanocomputador, proporciona um ambiente como se fosse uma parte do mundo real. De um ponto de vista tecnológico, a RV tornou-se possível pela capacidade dos computadores em sintetizar um ambiente gráfico 3D a partir de dados numéricos. Dispositivos de entrada diferentes percebem reações e movimentos dos usuários, enquanto o computador modifica o ambiente em conformidade, dando a ilusão de elementos/ambientes de interação e estar imerso neles. De um ponto de vista psicológico, a RV pode ser considerado um sistema imaginativo avançado: uma forma experimental de imagens que é tão eficaz quanto a realidade em induzir uma ampla gama de respostas cognitivas e emocionais (Gorini, Gaggioli, e Riva, 2010).

Embora tenhamos visto algumas definições de RV e algumas de suas características, estas não teriam fundamento e uso prático se o usuário não estiver profundamente envolvido nos cenários. Esse envolvimento pode ser chamado de uma sensação de imersão ou presença.

\subsection{Sentimento de Presença \& Imersão}

Para que um cenário seja eficiente, é necessário que o sentimento de presença seja forte. Vale ressaltar que o cenário, propriamente, contribui para que haja um sentimento de presença.

Gutierrez et. al. (2008) refere-se a presença como sendo um conceito subjetivo, associado com a psicologia do usuário e que pode levar ao envolvimento e a reações do mesmo. Isto nos reporta ao pensamento de Riva (2009) ao argumentar que a presença é um fenômeno psicológico amplo. Gutierrez et. al. (2008) salienta que é importante distinguir entre presença e envolvimento. Na vida real podemos estar presentes mas não envolvidos de fato. Podemos estar em algum lugar de forma física, presente, mas não agir em conformidade apesar de estarmos lá.

O comportamento dos usuários em RV pode ser influenciado pelos níveis de imersão, interação e imaginação (Burdea e Coiffet, 2003). Os níveis de imersão e interação estão normalmente dependentes dos equipamentos usados e das possibilidades de interação com os Envolvimentos Virtuais (EV). A imaginação está dependente dos itens anteriores e da natureza do contexto usado. Particularmente, em relação ao contexto, é importante dar ênfase a história, as tarefas que o participante deve executar e ao tipo de EV usado.

Dentro de um ambiente de Realidade Virtual ou de imersão virtual, o sentido de presença, segundo Baños et. al. (2004) tem sido geralmente considerado a chave da RV. Tradicionalmente, a RV tem sido aplicada em vários campos (Riva, 2005) tornando os participantes livres para explorar e gerir situações críticas em um ambiente de baixo custo mais controlado, ao invés de uma situação "ao vivo", ou no mundo real.

De fato, a RV tem sido proposta como um novo meio para expor o usuário em situações de risco e perigo (Gorini e Riva, 2008), que é mais seguro do que reproduzir 
situações do mundo real, sem problemas com questões éticas e com uma melhor relação custo-benefício.

De acordo com a literatura científica, a definição mais conhecida de presença é a apresentada pelo Lombard e Ditton (1997): a presença é uma função da nossa experiência de um dado meio, e especificamente a "ilusão perceptiva de não mediação" produzida por meio do desaparecimento do meio e a atenção consciente do assunto.

Vários pesquisadores têm realizado pesquisas experimentais neste sentido e podemos citar o trabalho de Gorini et. al. (2011) que, em um de seus experimentos, distribuiu 84 estudantes em quatro grupos para participar em um experimento onde eles deveriam encontrar um recipiente de sangue dentro de um hospital virtual em uma condição imersiva ou não-imersiva e com ou sem uma narrativa de carácter emocional relacionada. Os resultados mostraram que o fornecimento de uma narrativa que explica o contexto e o significado da experiência virtual produz um aumento significativo no nível de experiência de presença. Aparentemente, a variável de ligação entre "presença" e "significado" é a resposta emocional. A narrativa produz uma ativação fisiológica maior que fortalece a sensação de presença. A ligação entre a sensação de presença e as respostas emocionais tem sido identificadas como um assunto crítico para investigar.

\subsection{Metodologia}

A metodologia utilizada neste estudo para o desenvolvimento de cenários foi desenvolvida a partir de metodologias utilizadas em estudos de RV, metodologias da área do Design e reuniões com consultores externos. Sendo assim ela é composta, de forma geral, por 6 etapas conforme demonstrado na Figura 1, abaixo:

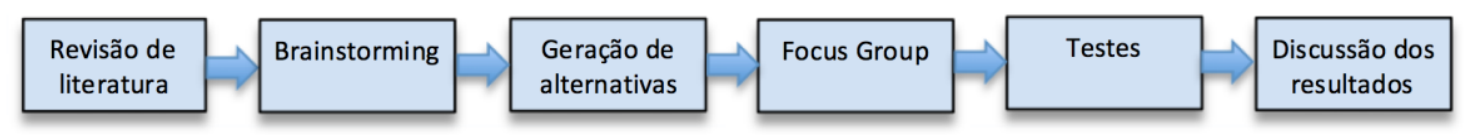

Figura 1 - Gráfico ilustrativo das 6 etapas utilizadas nesta metodologia.

Fonte: Elaborado pelo autor, com base na pesquisa realizada.

Na etapa 1, denominada revisão de literatura, procurou-se saber o que havia sobre influenciação dos cenários nas decisões das pessoas, tipo de comportamento, uso de avisos e estudos de casos. Na etapa 2: Brainstorming, composto por uma equipe multidisciplinar de 5 pessoas, constituída por ergonomistas e designers, foram geradas definições, parâmetros, imagens, normas de avisos e narrativas a serem utilizadas. Na etapa 3: geração de alternativas, a partir da etapa 2, foram geradas alternativas dos cenários. Na etapa 4: Focus Group, composta por 10 designers, ergonomistas e estudantes de design, foram analisadas a consistência dos cenários (de treino e final), quanto a legibilidade, compreensão dos avisos (ver figuras 3,4 e 5) e narrativa. Na etapa 5: testes, foi escolhido uma amostra de conveniência de 45 estudantes de design com faixa etária entre 18 e 30 anos distribuídos equitativamente entre gêneros. Este teste compreendeu uma primeira fase (pré-teste), com uma apresentação multimídia com 15 estudantes e posteriormente outro teste com o uso de e uma narrativa, imagem e um questionário em papel, com 30 estudantes. A etapa 6: Discussão e resultados, foram analisados os resultados decorrentes da etapa 
anterior, efetuado alterações e definiu-se, com auxilio de consultores externos, os 2 cenários de testes e os dois cenários finais.

O Ambiente virtual que suportou estes cenários foi desenvolvido a partir do software escolhido para modelação do contexto e implementação dos cenários, o Unity3D, (www.unity3d.com) que nos permite desenvolver ambientes virtuais complexos, no ambiente de interação intuitivo permitindo criar cenários virtuais de grande qualidade e com uma boa relação custo-benefício.

Durante o processo de implementação do contexto no Unity encontramos uma demonstração de um jogo chamado Bootcamp by Unity3D Technologies ${ }^{\circledR}$. Optou-se por esta solução por entendermos que ela atendia as nossas necessidades e, porque no futuro, pretende-se utilizar este mesmo envolvimento virtual em estudos com o uso da RV.

A nossa primeira proposta, dentro deste mesmo contexto, foram três cenários com avisos de diferentes níveis de explicitação do perigo, onde uma pessoa que andava pelo parque, subitamente ouvia explosões, recebia uma mensagem no celular avisando que ela corria risco de vida, que devia atravessar a ponte interditada. Ao deparar-se com esta ponte havia um aviso, em forma de placa situado em frente da entrada da ponte (Figura 2) e, a partir daí, ela deveria tomar uma atitude, ou atravessa a ponte interditada, mesmo o aviso dizendo para não fazê-lo, ou ia em direção da ponte segura há alguns metros adiante (também sinalizada). Entendemos após algumas reuniões que esta opção demonstrava-se inconsistente. A pessoa não tinha um envolvimento, um comprometimento suficientemente forte com o ambiente que poderia fazer com que ela não obedecesse o aviso. Soma-se a isto o facto de que tendo três avisos com diferentes níveis de explicitação das consequências, poderia induzir a um efeito "teto" onde todas as pessoas atravessassem a ponte.

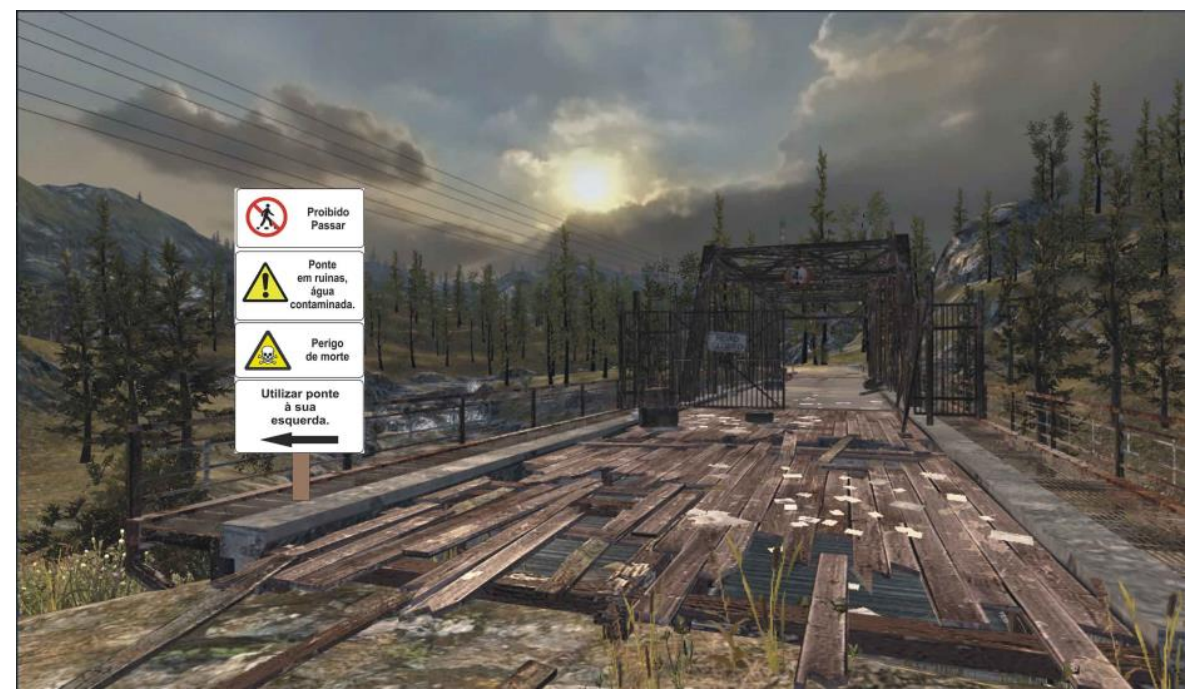

Figura 2 - Imagem com avisos.

Fonte: Imagem do jogo Bootcamp by Unity3D, adaptada pelo autor, com base na pesquisa realizada.

A segunda proposta foi desenvolvida ainda com o mesmo contexto, mas optamos por usar apenas um aviso de "proibido passar", na forma de mensagem, no celular e não mais uma placa, pois nesta etapa o objetivo era verificar se as pessoas atravessariam ou não a ponte diante de um aviso e não analisar a consistência deste. 
Para além disto, não fazia sentido utilizar um aviso de base tecnológica estático no meio de uma reserva florestal.

Antes da proposta final, houve um terceiro desenvolvimento onde utilizou-se, para efeitos de um teste piloto com o intuito de testar a eficiência destes cenários, uma apresentação multimídia (com o uso do programa Power Point, Microsoft ${ }^{\circledR}$ ). As imagens (Quadro 1) são apresentadas na sequência de apresentação, para ambos os cenários, como segue abaixo:

Quadro 1- Imagens que exemplificam os cenário egoísta e altruísta, de treino e final, desta fase.

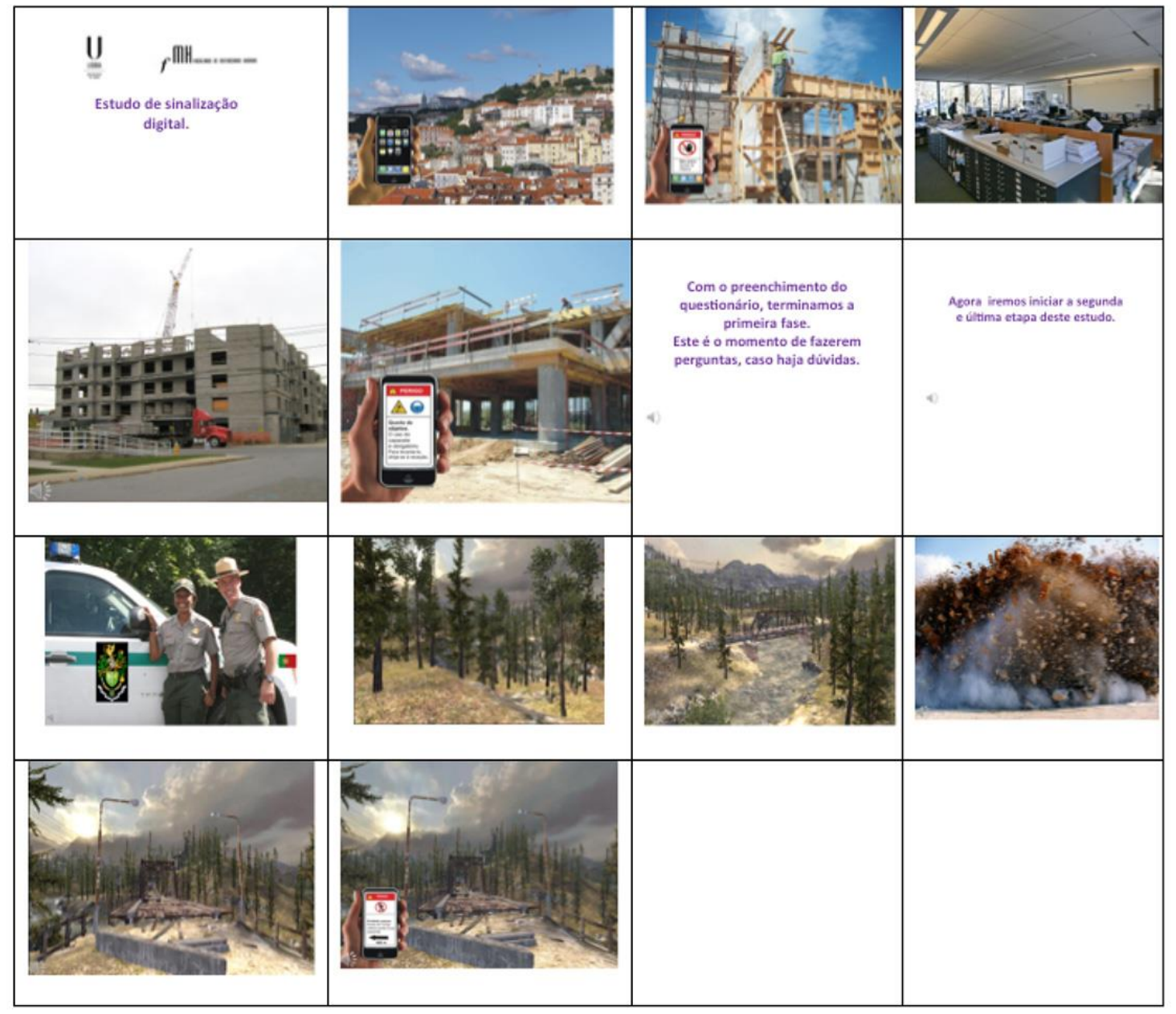

Fonte: Imagens retiradas da internet e do software Bootcamp by Unity3 ${ }^{\circledR}$ e adaptadas pelo autor.

Utilizou-se um mesmo ambiente para ambos os cenários, caracterizado por um terreno em campo aberto e acidentado, preenchido com árvores, rochas e elementos construídos, tais como casas, pedreira, um rio e uma ponte. Definimos, a partir da fase 5: Testes, que o participante deveria estar mais envolvido com o ambiente e decidimos que ele seria um guarda florestal. Após verificar os resultados de um pré-teste, as justificações dadas por eles em relação as intenções comportamentais, levaram-nos a concluir que estava ocorrendo respostas "socialmente adequadas" ou "comportamento socialmente desejável" e resolvemos mudar a narrativa para a terceira pessoa para solucionar este problema. Sobre esta questão, Park and Kim (2013) identificam que Davison (1983) foi o primeiro que cunhou a hipótese de efeito de terceira pessoa, como a tendência a presumir que os outros vão ser mais suscetíveis 
aos efeitos negativos do público do que eles. As pessoas tendem a esperar que a exposição ao público produza um efeito maior sobre os outros do que em si mesmos. Relativo às respostas socialmente adequadas, Pitesa et. al. (2013), demonstram em um estudo que o comportamento das pessoas tende a ser socialmente desejável, frente ao impacto de uma ação interpessoal saliente ou importante.

Procurou-se criar uma situação extrema, na qual o indivíduo fosse levado a desobedecer o aviso (inserido em um celular que está em um ambiente virtual). Este aviso é dinâmico e de base tecnologia. Para operacionalizar isto, pensou-se em situações de risco de vida que são, naturalmente, aquelas cujos fins justificam os meios. Sendo assim procurou-se utilizar comportamentos opostos que pudessem influenciar na decisão do usuário.

Tanto para as imagens utilizadas no Quadro 1, como para os resultados finais encontrados no item abaixo e as narrativas desenvolvidas, foram utilizadas com o objetivo de proporcionar ao usuário um aumento significativo no nível de presença conforme foi visto no item 2.3. Como este estudo foi desenvolvido com imagens e narrativas em papel, a partir de um ambiente virtual, estas imagens e as narrativa assumem uma importância fundamental para aumentar e tornar mais eficiente a sensação de imersão e presença.

\section{RESULTADOS}

Esta metodologia culminou com o desenvolvimento de dois cenários distintos (altruísta e egoísta), compostos por cenários de treino e cenários finais.

Convencionou-se chamar de "altruísta" a situação onde há riscos para terceiros. Utilizou-se uma imagem (Figura 3) e uma narrativa composta do seguinte texto:

"Imagine que hoje é o primeiro dia de trabalho do João na Serra da Arrábida como guarda-florestal. A área de trabalho dele compreende uma grande floresta que abrange um rio, pontes, uma pequena vila e uma pedreira. Ele está junto a uma ponte interdita, que atravessa um rio muito perigoso. Para evitar afogamentos, o acesso ao rio está vedado por barreiras intransponíveis. Neste momento o João vê um pequeno foco de incêndio que deflagrou no bosque, na outra margem e pode se alastrar. A tarefa dele é deslocar-se imediatamente para lá, para apagar o fogo, antes que ele assuma proporções não controladas e coloque em perigo a vida das pessoas que vivem na vila próxima".

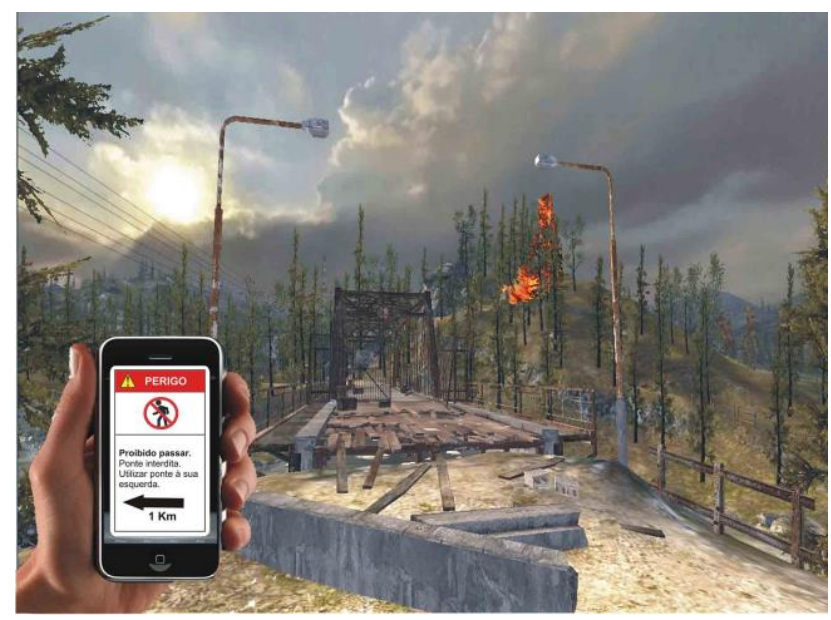

Figura 3 - Cenário altruísta final com aviso.

Fonte: Imagem obtida do envolvimento virtual do jogo Bootcamp by Unity3 ${ }^{\circledR}{ }^{\circledR}$, adaptada pelo autor. 
Optou-se por chamar de "egoísta" a situação de risco para si próprio. Para isto utilizou-se uma imagem (Figura 4) e a seguinte narrativa:

“Imagine que hoje é o primeiro dia de trabalho do João na Serra da Arrábida como guarda-florestal. A área de trabalho dele compreende uma grande floresta que abrange um rio, pontes, uma pequena vila e uma pedreira. Ele está junto a uma ponte interditada, que atravessa um rio muito perigoso. Para evitar afogamentos, o acesso ao rio está vedado por barreiras intransponíveis. Neste momento o João vê e ouve explosões muito fortes, ao seu redor e ao longo da margem do rio onde se encontra, provenientes de uma pedreira muito próxima. As vibrações das explosões fazem tremer o chão onde está e há fragmentos de pedra no ar, perto dele, que podem matá-lo se continuar deste lado da margem".

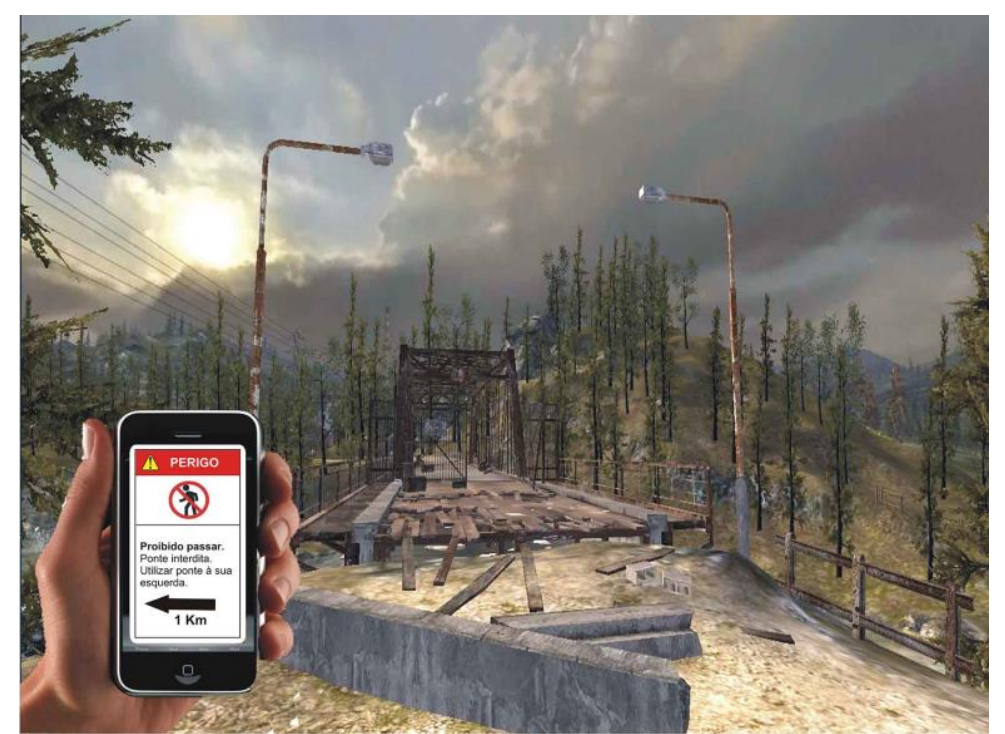

Figura 4 - Cenário egoísta final com aviso.

Fonte: Imagem obtida do envolvimento virtual do jogo Bootcamp by Unity3D ${ }^{\circledR}$, adaptada pelo autor.

Entendeu-se que seria provável que houvesse pesos distintos entre os dois cenários e consequentemente que fossem percebidos pelas pessoas. Na sequência de cada narrativa foram utilizadas imagens distintas provenientes do jogo chamado Bootcamp by Unity3D Technologies ${ }^{\circledR}$. Foram adaptadas imagens conforme as características da narrativa de cada cenário (Figuras 3 e 4). Para esta adaptação utilizou-se o software Adobe Photoshop CC ${ }^{\circledR}$. Foram utilizados avisos consistentes com as propostas de harmonização ANSI-ISO e adaptados com o uso do software Corel Draw $^{\circledR}$.

Entretanto, entendemos que não bastava desenvolver apenas os cenários principais para a pesquisa. Em um ambiente virtual é importante que o usuários tenham uma adaptação prévia ao ambiente e narrativa que ele irá encontrar e, devido a isto, decidimos desenvolver mais dois cenários de treino, um para cada situação experimental. Os dois cenários de treino antecedem os principais e mantém as mesmas características citadas acima, no que se refere aos dilemas, mudando apenas a narrativa, para se adaptar as duas situações experimentais (Egoísta e Altruísta), (Figuras 5 e 6). 


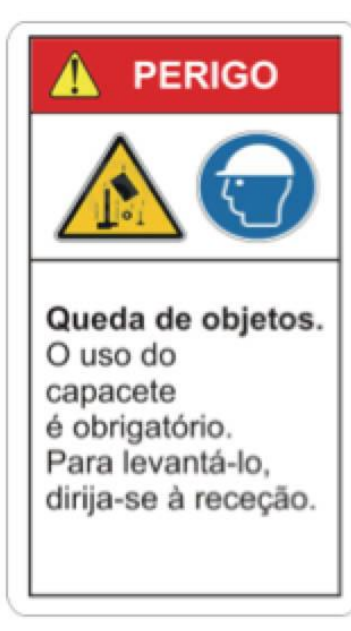

(5)

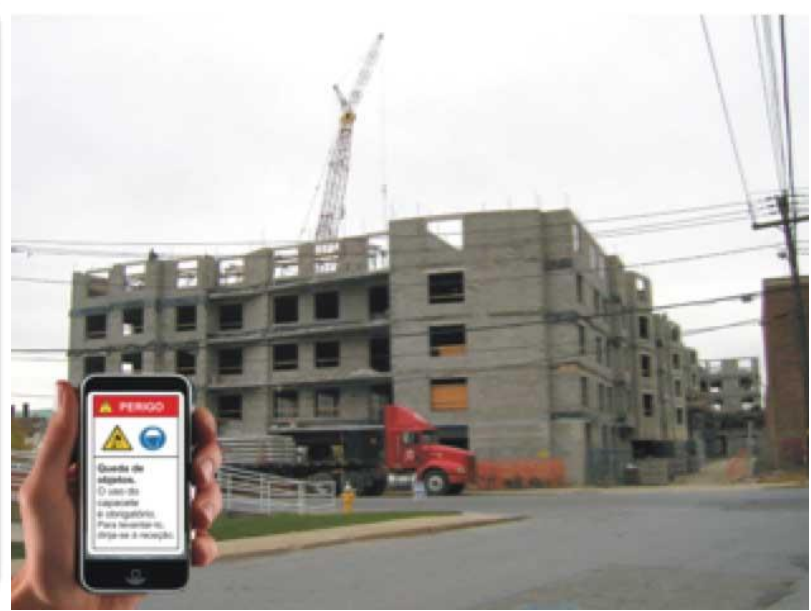

(6)

Figura 5 - Aviso: Perigo queda de objetos.

Fonte: Elaborado pelo autor, com base na pesquisa realizada.

Figura 6 - Imagem de um edifício em construção com aviso.

Fonte: Imagem retirada da internet e adaptada pelo autor.

Embora o objetivo deste estudo não tenha sido avaliar os avisos, entendemos ser importante contextualizar o uso destes com o emprego de imagens obtidas do envolvimento virtual do jogo Bootcamp by Unity $3 D^{\circledR}$, (Figuras 3 e 4) com uma montagem, para permitir a inserção do aviso. A Figura 6 corresponde a uma imagem retirada da internet que foi escolhida pelos pesquisadores por entenderem a que melhor representava a narrativa utilizada no cenário de treinamento. A importância desta contextualização com imagens se deve ao facto da necessidade de proporcionar um maior envolvimento por parte do usuário.

As duas narrativas utilizadas para os cenários de treino foram iguais, exceto as frases finais, onde têm-se: (a) para altruísta e (b) para egoísta, como segue abaixo:

Estamos a testar um sistema de avisos de segurança, que tem como suporte um celular com georreferenciação (GPS), isto é, que é capaz de localizar uma pessoa em determinado local no globo terrestre, de forma rápida e precisa. Este sistema avisa a pessoa através de mensagens e imagens, na tela do celular, da existência de perigos que possam colocar em risco a sua vida, e proporciona um conjunto de informações para a sua proteção.

Imagine que o João é um engenheiro, trabalhando num gabinete de estudos e projetos e está envolvido na análise do planeamento de uma nova urbanização, próxima ao seu bairro. Ele acabou de receber de um colega de gabinete a informação que necessita se deslocar ao local da urbanização, para ter uma reunião de trabalho. $O$ João desloca-se à urbanização e:

(a) Ao chegar, ouve de longe um pedido de socorro de um trabalhador que sofreu um acidente e está gravemente ferido dentro da obra.

(b) Na entrada, recebe uma mensagem de um colega com a seguinte informação: “O cliente está no quarto andar da obra e tem uma dúvida. Ele necessita falar consigo imediatamente. Se você não comparecer a tempo, a obra irá atrasar-se e os prejuízos serão imensos".

\section{CONCLUSÃO}

O objetivo deste artigo foi desenvolver uma metodologia para a criação de cenários, o que implicou demonstrar as fases de seu desenvolvimento e os resultados obtidos. Os dois cenários desenvolvidos são divergentes entre si no que se refere ao 
comportamento do usuário frente as narrativas, os contextos e os ambientes virtuais desenvolvidos. Os resultados apresentados no item acima, além de terem alcançado os objetivos propostos, são uma primeira etapa de um estudo onde, em uma próxima pesquisa, será testado qual destes dois cenários exerce maior influência no usuário frente a uma tomada de decisão com um aviso estático consistente com as propostas de harmonização ANSI-ISO.

No seguimento destas etapas, um outro estudo utilizará o cenário selecionado em um ambiente virtual para testar um aviso multimodal, onde pretende-se utilizar a RV. Além das características de imersão proporcionarem um maior envolvimento do usuário e, também, o uso de algumas características tipicamente encontradas em situações de emergência, como o ruído e fogo, a RV é melhor indicada para poder-se avaliar a consonância comportamental. Isto irá permitir uma melhor avaliação com avisos de segurança dinâmicos em situações críticas.

\section{AGRADECIMENTOS}

Esta pesquisa foi financiada com uma bolsa de estudos pela Coordenação de Aperfeiçoamento de Pessoal de Nível Superior (CAPES, Brasil), através do processo BEX 6210-10-4, para Reginaldo Schiavini.

\section{REFERÊNCIAS}

ALEXANDER, Ian; MAIDEN, Neil. Scenarios, stories, use cases: through the systems development life-cycle. West Sussex: J. Wiley, 2004.

BAÑOS, R.M. et. al. Immersion and emotion: their impact on the sense of presence. Cyberpsychology \& Behavior, v.7, no 6, p.734-741, 2004.

BURDEA, Grigore; COIFFET, Philippe. Virtual reality technology. Hoboken, NJ: J. Wiley, 2003.

CARROLL, John Millar. Making use: scenario-based design of human-computer interactions. USA: MIT Press Cambridge, 2000.

COOK, Malcolm et. al. Decision making in complex environments. USA: Ashgate, 2007.

DAVISON, Phillips. The third-person effect in communication. Public Opinion Quarterly, v.47, no 1, p. 3-15, 1983.

DUARTE, Emilia et. al. Behavioral compliance for dynamic versus static signs in an immersive virtual environment. Applied Ergonomics, p.1-9, Nov. 2013.

FELTOVICH, Paul, J. et. al. Learners' (mis)understanding of important and difficult concepts: a challenge to smart machines in education. In: Forbus, Kenneth D.; Feltovich, Paul, J. (ed.). Smart machines in education. Menlo Park, CA: AAAI/MIT Press, 2001.

GORINI, Alessandra et. al. The role of immersion and narrative in mediated presence: the virtual hospital experience. Cyberpsychology, Behavior and Social Networking, v.14, no 3, p. 99-105, 2011. 
GORINI, Alessandra; GAGGIOLI, Andrea; RIVA, Giuseppe. Virtual reality as an experiential tool: the role of virtual worlds in psychological interventions. In: MOHAMMED, Sabah; FIAIDHI, Jinan (ed.). Ubiquitous health and medical informatics: the ubiquity 2.0 trend and beyond. New York: Medical Information Science Reference, p. 532-551, 2010.

GORINI, Alessandra; RIVA, Giuseppe. Virtual reality in anxiety disorders: the past and the future. Expert Reviews Neurotherapeutics, v.8, no 2, p. 215-233, Fev. 2008.

GUTIERREZ, Mario; VEXO, Frederik; THALMANN, Daniel. Stepping into Virtual Reality. Santa Clara, CA: Springer-Verlag Telos, 2008.

LAUGHERY, Kenneth R.; SMITH, Danielle P. Explicit information in warnings. In: WOGALTER, Michael S. (ed.). Handbook of warnings. Mahwah, NJ: L. Erlbaum, p. 419428, 2006.

LAUGHERY, Kenneth R.; WOGALTER, Michael S. Warnings and risk perception. In: SALVENDY, Gavriel (ed.). Handbook of Human Factors and Ergonomics (2nd ed.). New York: Wiley, p. 1174-1197, 1997.

LOMBARD, Matthew; DITTON, Theresa. At the heart of it all: the concept of presence. Journal of Computer-Mediated Communication, v.3, no 2, 0, Set. 1997.

PARK, Sun-A.; KIM, Jeesun. Social categorization and cross-cultural exploration of the third-person effect: perceived impact of North Korea's nuclear test on the self and comparison targets. Studies in Communication Sciences, v.13, no 1, p. 50-57, Apr. 2013.

PITESA, Marko; THAU, Stefan; PILLUTLA, Madan M. Cognitive control and socially desirable behavior: the role of interpersonal impact. Organizational Behavior and Human Decision Processes, v.122, n², p. 232-243, Nov. 2013.

RIVA, Giuseppe. The Psychology of Ambient Intelligence: Activity, Situation and Presence. In: RIVA, Giuseppe et. al. (ed.). Ambient Intelligence. Amsterdam: IOS Press, p. 17-33, Jan. 2005.

RIVA, Giuseppe. Presence as cognitive process. In: BENYON, David; SMYTH, Michael; HELGASON, Ingi. (ed.). Presence for everyone: a short guide to presence research. Edinburg: Centre for Interaction Design Edinburgh Napier University, p.29-31, 2009.

WOGALTER, Michael S.; CONZOLA, Vincent C. Using technology to facilitate the design and delivery of warnings. International Journal of Systems Science, v.33, p. 461-466, Nov. 2002.

WOGALTER, Michael S.; MAYHORN, Christopher B. Providing cognitive support with technology-based warning systems. Ergonomics, v. 48, no 5, p. 522-533, Apr. 2005. 